\title{
The Anatomy Lecture Then and Now: A Foucauldian Analysis
}

From Leonardo's Anatomical Notebooks (c 1510), through Vesalius' 'Humani Corpus Fabrica' to Eakin's 'The Gross Clinic' (1875), instruction in and demonstration of the structure and function of the human body has been a highly visible aspect of medical education. Despite its celebrated status in medical and other histories, few have linked this illustrious past with the present in terms of the pedagogy and technique of the anatomy lecture. At the same time, however, the evaluation of the instructional effectiveness of the anatomy lecture as an amalgam of didactic techniques - particularly as modified via podcasts and for increased student participation-is a topic of ongoing interest in the literature of medical instruction (e.g., Brown and Manogue 2001; McNulty et al. 2012; Prober and Heath 2012; Schreiber et al. 2010). Other studies (Roth and Bowen 1999b; Roth et al. 1997) suggest that certain scientific phenomena are difficult or impossible to properly understand unless their structures and functions are demonstrated through traditional lecture forms. This includes the talk and gestures of the lecturer, as well as informal inscriptive practices (e.g. on the blackboard). At the same time, the lecture, these traditional lecture practices, independent of disciplinary context, are currently widely regarded as outmoded and unnecessary (e.g., Friesen 2011; Prober and Heath 2012), and its stubborn persistence has been condemned as the result only of 'enfeeble[ing] tradition' (Laurillard 2002, p. 93).

Taken together, these different observations and assertions raise a variety of questions about the lecture: If the science lecture has changed in the last 500 years, in what ways has it changed? Is its persistence to be explained only in terms of enfeebling tradition or of a few scientific phenomena that may not be communicable any other way? Or are there other factors involved?

As we show in this paper, there are in fact a number of changes in the pedagogical form of the anatomy lecture over the longue durée, over centuries, rather than years or decades. In Michel Foucault's work, particularly in The Order of Things: An Archaeology of the Human Sciences, these periods of long duration are referred to as epistemes: They are epistemological and discursive configurations or formations, whose continuity (as is the case for the longue durée generally) is interrupted by brief periods of relatively rapid transition and reconfiguration. It is this Foucauldian conception of epistemic and cultural change that is central to our analysis in this paper.

Foucault has conventionally been interpreted in educational philosophy as offering a critique of the hegemonic exercise of power/knowledge in educational forms and practices. Classrooms and educational institutions and discourses have been seen as mechanisms that are emblematic in subject formation or production (e.g., Popkewitz \& Brennan, 1998). However, as Leask (2012) has argued more recently, the interpretation of Foucault through his later works (e.g. on pastoral power) would see schools and lecture halls not as 'factories of obedient behavior', but as instantiating power relations that are much less unidirectional and unambiguous. In their ambivalent tensions, these institutions and processes can be seen as being not simply forms of control but also as 'creative, enabling and positive' (p. 57). In further contradistinction to many Foucauldian analyses in education, our concern in this paper does lie explicitly with subject-formation, but as 
already indicated, with the historical and epistemic questions characteristic of the early Foucault. With this shift in emphasis, we seek to re-deploy the critical impulse of Foucault's work from a critique of the exercise of power in the classroom to (a) the broader process of the reproduction and validation of knowledge in general and (b) the

role of pedagogical techniques and technologies therein. In the context of the classical and modern epistemes of Foucault, our intention is not to show that technological change is now forcing us into a moment of inter-epochal revolution, as many have attempted to argue (e.g., Collins and Halverson 2010). Instead, we illustrate that (a) current frames of reference were anticipated already in the $16^{\text {th }}$ and $17^{\text {th }}$ centuries and (b) the contemporary lecture is marked by the exclusion of, rather than an adaptation to new educational technology and media. The paper begins with an analysis of the physical and technical arrangements of the anatomy lecture from both the early modern period and our 'late' modern epoch, showing how these present a general underlying continuity for this pedagogical form. It then goes on to consider elements of speech and presentation, description and illustration that are used in the medical and biology lecture, specifically in its description of and accounting for the operation of the heart, from the early modern (16-17 $7^{\text {th }}$ centuries) and late modern (or contemporary) eras. In the former, we use the text of William Harvey's lectures from 1616; in the latter, we use audio/video recordings of high school lectures for analysis. In this manner, this paper traces the way in which the anatomy lecture demonstrates a basic physical and technical continuity in the classroom or theater, and how at the same time the types of larger epistemic functions it has are changing. This transition starts from a descriptive, discursive role, focusing on individual organs and their physicality to one that is more integrative, systemic and also performative in both form and content.

\section{Background: The Anatomy Lecture Today}

The contemporary lecture analyzed in this paper (e.g., figure 1, below), presents an inscription-centered configuration, in which the speaker is oriented to whatever appears on or near the chalkboard behind him or her (Roth and Lawless 2002b). The centrality of inscriptions is clear in the example here, in which the teacher is talking over and about a diagram of the female reproductive organs generally, and focusing on the uterus and pelvis through which the child travels during birth. As can be seen, the inscriptions are rather rough, and the teacher seems to have deliberately eschewed the many other, more technically advanced options for presentation: an unused overhead projector is visible in the lower-left foreground. 


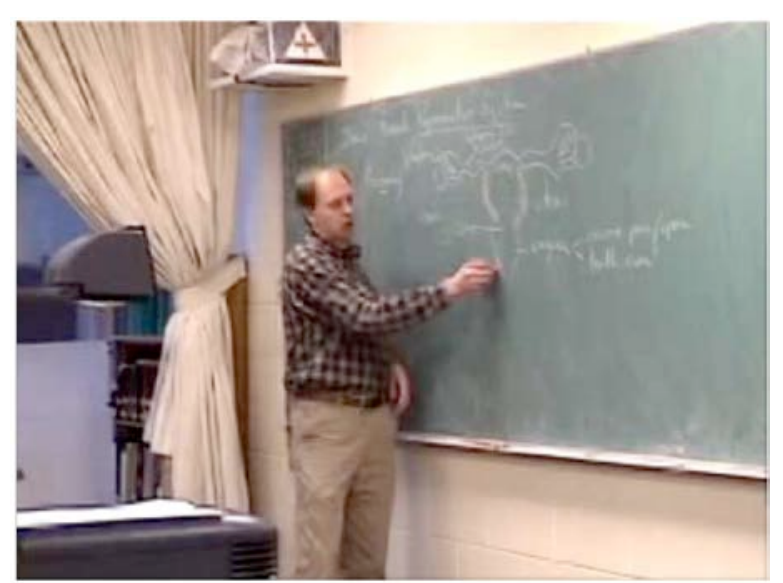

Figure 1: A contemporary lecture presents aspects of reproductive physiology over and against a diagram of the female reproductive organs.

What has this instructor chosen to do instead? He engages in hand/arm movements, first those of drawing the image and then retracing its lines and thereby highlighting, outlining, or encompassing features of importance (Pozzer-Ardenghi and Roth 2005). The gestures he enacts can be described as deictic, pointing to things in the context provided by the diagram. This context, from the lecturer to the board, can be said to constitute a deictic space, a context of pointing, drawing and indication.
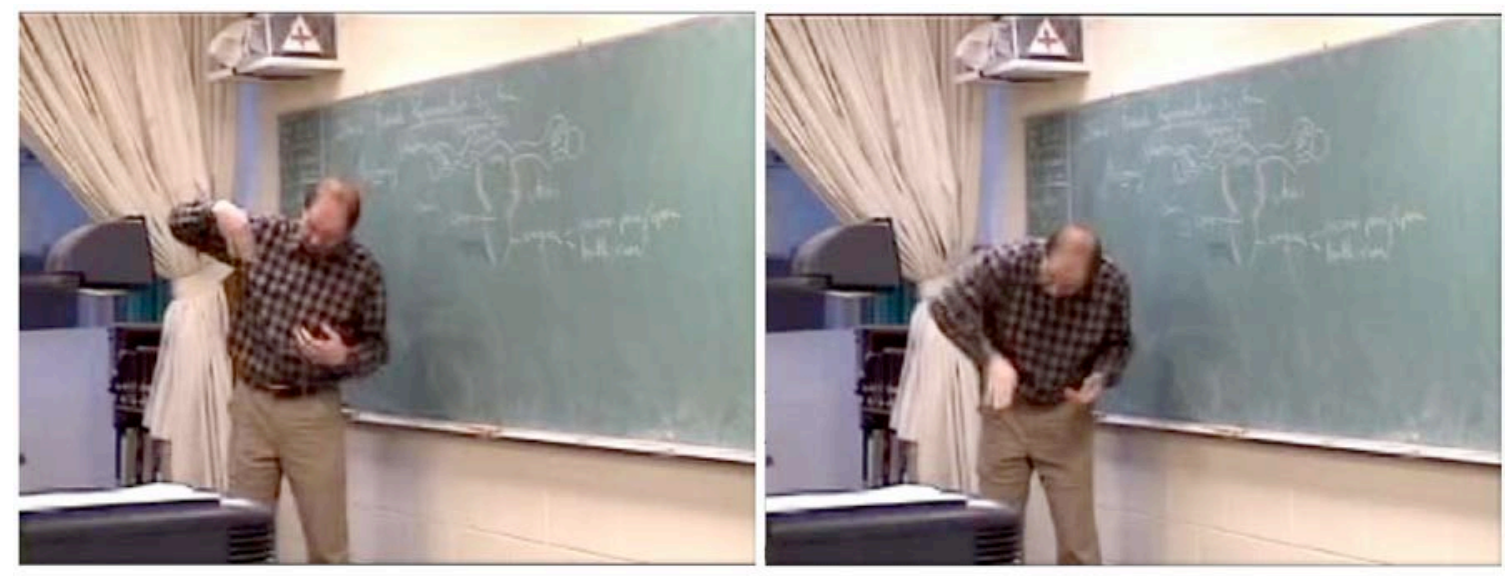

Figures 2 and 3: An iconic illustration of reproductive physiology.

The other type of gesture central to this lecture is iconic. As shown in figures 2 and 3 below, the teacher performs the movements undergone by the fetus in the process of exiting the uterus and moving through the birth canal past the pelvis. These gestures are iconic in the sense that they imitate objects, actions or events - in this case, the action of the fetus, uterus and pelvis in the event of childbirth. These gestures do not occur in the deictic space between the teacher and the diagram; instead, they occur in a second space that is fundamental to the lecture: the narrative space, which extends from the lecturer out to the audience. In this situation, the lecturer enacts a birth, as if he were following a baby through the birth canal and out into the open. In some situations - such as the 
illustration of a knee-jerk reaction in the doctor's office, or the location of specific organs, additional attentional work is required to distinguish whether the lecturer's body pointed to is his/her own or a generalized body (Pozzer-Ardenghi and Roth 2009). These two gestural spaces, deictic and iconic, are opposed, with each drawing the lecturer's body and attention to points separated by 180 degrees (Roth and Lawless 2002b).

Science lectures often include many different forms of presentations, descriptions, drawings, models, or diagrams on the chalkboard, physical models, overhead projections, slides, and so on (Roth and Bowen 1999a). Over time, these instructional 'realia' have changed. In the case of the anatomy lecture, they have generally begun with the progressive dissection of a cadaver, later encompassing various visual representations in print - e.g., the detailed anatomical images Descartes (1664) produced of hear and circular system, eyes with nerves and muscles, and so on; and today, they can include sophisticated digital imaging and presentation technologies. But these developments raise a number of questions, most notably: Why is the instructor above (and in the examples studied below), working largely independently of these technologies or realia? How is this teacher, or instructors of anatomy, physiology and biology more generally, able to communicate efficiently in this context? Finally, what does this say about the epistemology - the understanding of knowledge and of the process of teaching itselfunderlying the lecturer's performance?

\section{The Anatomy Lecture in the early $16^{\text {th }}$ Century}

Figures 4 to 6, below, are from the frontispiece from the 1543 edition of Vesalius' De Fabrica corpis humani, the first comprehensive, illustrated anatomy book. Pedagogical structures and functions manifest in this illustration can be analyzed using the frame of reference provided just above: Despite its chaotic appearance, in pedagogical terms, the illustration is divided into two spaces, deictic and narrative. Also, as with the lecturer analyzed above, Vesalius' body marks the axis between the two spaces, in effect inhabiting both simultaneously_-indeed appearing to be evenly split across the two. In an overt sense, Vesalius' own body is directed toward the cadaver, the deictic space, in which he is pointing out the details of the corpse before him (figures 5 and 6) indicate, his attention is actually directed to his audience, with the image illustrating, even with some exaggeration, his glance directed toward his audience. Vesalius' right hand appears to (a) direct attention to and (b) make visible the organs that have become visibly accessible following an incision. His left hand, visible just above his right sleeve, appears to have a kind of narrative function, pointing upwards as if in a rhetorical gesture. This is a gesture that appears neither strictly iconic nor deictic but interactive (e.g., Bavelas et al. 1992), allowing the audience to note the importance of his point in the making. In other words, without straining the viewer's credulity, Vesalius is made to appear to be engaged in two if not three gestures simultaneously, all of them expressive of his role as lecturer and anatomist: With his right he both points to and holds open an incision, and with his left, he is engaging his audience.

It is the dissected body, however, that offers perhaps the clearest point of differentiation from the lecture analyzed above. This is an elaborate, vivid realia that 
obviously would not be easy to accommodate in a contemporary introductory biology classroom - though it is not uncommon to find heart dissections in senior biology courses (e.g., Richardson Bruna and Vann 2007; Weinstein and Broda 2009). At the same time, the lecturer in the contemporary classroom would have many other options at his disposal. How are these points of contrast to be understood? One way to answer this question, and to also understand further differences separating the early modern anatomy lecture from its $21^{\text {st }}$ century counterpart, is to consider and compare the more general conditions and contents of the performance of lectures of this kind and the historical reproduction [Nacherzeugung] and 'reunderstanding [Nachverstehen]' of corresponding forms of knowledge (Husserl 1976) during each era.

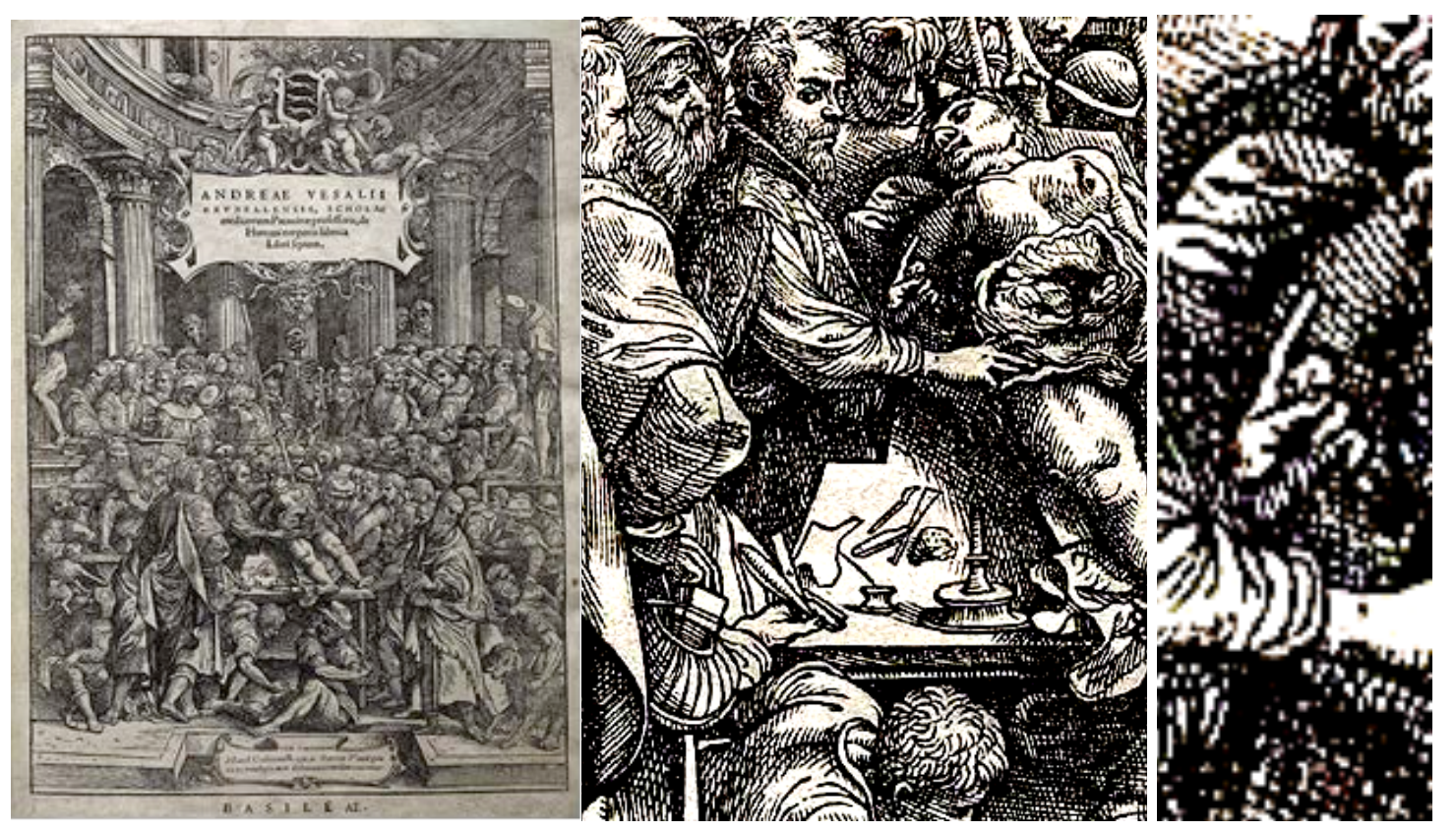

Figure 4-6: Cover from Vesalius' De Fabrica corpis humani, with details.

\section{Motions of the Heart: Harvey's Lumleian Lectures}

William Harvey, an anatomist working roughly a century later than Vesalius, is best known in the history of science for describing the 'circulatory system' in terms that correspond with those we use today. Vesalius understood the flow of fluids through the body in terms of four humors. Such an understanding - with the four humors corresponding to four tempers and four physical elements - is illustrative of one of the epochal epistemological configurations central to Foucault's historical analyses. This is the late-medieval, Aristotelian order of things or episteme that Foucault describes as working in terms of 'resemblance'. All the substances that could be encountered are ordered in terms of their resemblance to water, air, earth and fire, and this includes the substances of the body (blood, phlegm, and black and yellow bile, respectively). These in turn correspond to the four seasons, and to four (categories of) bodily organs. The preponderance of any one of the four elements in the body corresponded with 
characteristics of one's temperament that in turn resembled a particular element and season. Yellow bile, for example, meant a choleric or short-tempered character, corresponding to fire and the heat of the summer. ${ }^{1}$ Thus,

$[u] p$ to the end of the sixteenth century, resemblance played a constructive role in the knowledge of Western culture. It was resemblance . . . that organized the play of symbols, made possible knowledge of things visible and invisible, and controlled the art of representing them. The universe was folded in upon itself: the earth echoing the sky, [and] faces seeing themselves reflected in the stars. (Foucault 1970, p. 16)

The echoes that Foucault invokes, as shown below, still reverberate in the lectures of Harvey, where references to humors and Aristotelian anatomy crop up relatively frequently. From a philosophical-epistemological perspective, therefore, Harvey is one of the transitional figures between what subsequently have come to be recognized as two eras: the medieval scholastic and the emerging scientific one (Gilson 1920). In a clear departure from this pre-classical 'order of resemblance', Harvey not only provides in his lectures a relatively new account of the heart's anatomy (its form) but also its physiology (its function). In fact, Descartes' (1664) work on the human body published 20 years after Harvey's De motu cordis (Harveius 1628) was closer to the scholastic, Aristotelian position than to modern science. For Harvey, on the other hand, the heart was no longer a means of regulating the phlegmatic disposition of the lungs (by mixing blood with air, as Aristotle and other ancients thought). Instead, the essential outlines of the heart and its function articulated by Harvey continue to be the same ones taught to the present daywhich is why he is celebrated today as the father of modern anatomy and physiology' '. In fact, Harvey's account and elements of his biography together constitute a paradigmatic case of the epic character of the sciences (van Eijck and Roth 2011). The descriptions of the movements of the heart available in Harvey's lectures consequently provide us with a basis for understanding the differences in pedagogy and content that separate current lectures on the heart from those of some 400 years ago.

Unlike the gestures of Vesalius and the classroom teacher discussed above, the context and exigencies associated with William Harvey's lectures on anatomy are less than self-evident to the contemporary reader, and therefore require some description and explanation. First, Harvey's lectures were not part of a standardized curriculum: they were founded by, and sometimes had as their audience, members of royalty and the nobility. In this case, they took their name from Lord Lumley, who was their initial sponsor, and they continue to be held this day, still bearing his name. 'The rules drawn up for the Lumleian lectures', as a $20^{\text {th }}$-century reissue of these texts explains, 'were in the best tradition of medical education [of the time]: read the authorities, comment on the texts, expound their application' (Whitteridge 1964, p. xxx). This meant that Harvey's

\footnotetext{
${ }^{1}$ To be fair to Vesalius, it is important to note that he did much to dispel some beliefs about human anatomy that were a part of the medieval 'order of resemblance'. For example, he used an actual human body in his anatomical lectures and research; and he rejected certain observations made by the ancient anatomist Galen, who, as Vesalius had discovered, had used only apes in his dissections.
} 
lectures were 'in effect a commentary', on an already existing text (written a few years previously, by Caspar Bauhin). The ostensible purpose of the commentary was to allow Harvey to add his own observations and clarifications specifically to a then famous textbook on anatomy. Harvey read aloud passages from this text, commented on them, and added some of his own observations (as well as observations from various ancient and contemporary authorities). Thus,

Harvey's normal procedure is to follow Bauhin's description and jot down sufficient words and phrases to remind himself of the whole. Sometimes he includes whole sentences verbatim. Into this framework, Harvey introduces his own remarks and comments and references to other authorities. ... His own opinions are usually initialled $\mathrm{WH}$, but not always, and they have to be disentangled from the non-original material. (Whitteridge 1964, p. xxxii)

The passages from these lectures quoted below are from a careful reconstruction of Harvey's notes or commentary. Some of the underlying differences separating Harvey's lectures from the expositions that occurred in earlier centuries - and from ones that occur today - can be gleaned from Harvey's own 'General Rules for an Anatomy' outlined at the beginning of his Lumleian lectures. These rules amount to little less than a programmatic statement of the procedures and beliefs that Harvey mobilizes in the rest of his exposition; and they include: '5. Review your own and other people's observations in order to consider carefully your own opinion . . . according to the rules of Socrates [for developing arguments by means of analogies]' (Harvey 1964, p. 17). At the same time, however, Harvey's rules for the anatomy lecture point to a second source of authority in establishing anatomical knowledge. ${ }^{2}$ For example, he recommended that anatomists:

2. Point out the peculiarities of the particular body, and the things that are new or but newly discovered

3. To supply only by speech what cannot be shown, on your own credit and by authority. .. . Briefly and plainly, yet not letting pass any one thing unspoken of which is subject to view. (Harvey 1964, p. 17)

Harvey here is appealing to the validity of that 'which is subject to view'. If this happens to be something that is 'new or but newly discovered'-in other words, something not already observed by the likes of Aristotle, Galen, Vesalius, or Bauhinthen it should be clearly pointed out. In the scientific lecture, then as now, the new (and possibly revolutionary) thereby comes to be staged against the knowledge handed down from the ancients (e.g., Roth and Tobin 1996). Empirical observation and received tradition are thus to be taken under consideration together in the anatomists' work.",

\footnotetext{
${ }^{2}$ Harvey lists 12 'general rules' or Canones Anatomae Generales many of which (not quoted here) support the authority of empirical knowledge gained from the dissection, balanced with a qualified affirmation of ancient and more recent authorities in anatomy. A number of these rules also affirm the importance of efficient use of time in dissecting the cadaver, since preservation and refrigeration technologies were then unknown.
} 
In addition to these two sources of authority, Harvey's rules also underscore a particular technique, of clear relevance to pedagogy, but also in keeping with the authorization of knowledge in his own time. This is the importance of speech and language: 'Supply only by speech that which cannot be shown' without leaving 'any one thing unspoken ... which is subject to view'. Everything in the cadaver being dissected, both the visible and the invisible, should be rendered into speech; also, empirical observations from earlier dissections (and also vivisections) which are also not visible in the lecture are to be included as well. Finally, Harvey recommends that for "each part of the body ... there are five aspects to consider 1. situation, 2. shape, 3. amount, 4. movement, 5, division' (1964, p. 21).

Harvey's simultaneous emphasis on rendering all into speech, and pointing out all 'the peculiarities of the particular body'-including situation, shape, amount, movement, division - are directly illustrative of Foucault's account of the classical episteme:

there exists a single, necessary arrangement running through the whole of the Classical episteme: the association of a universal calculus and a search for the elementary within a system that is artificial and is, for that very reason, able to make nature visible from its primary elements right to the simultaneity of all their possible combinations. (Foucault 1970, p. 61)

The necessary, artificial arrangement or system that Foucault says subtends classical discourse is that of the sign. In the classical age, the sign labels that which is in the natural world, and it makes it visible in its 'primary elements'. In this way, the classical age highlights the apophantic function of language: to let something (here the natural world) show itself as something in its togetherness with something (in this case, language) (Heidegger 1977). The sign does much more, though: The artificial system of language and of the sign also models the 'possible combinations' of the primary elements it makes visible. It thus serves as a kind of 'universal calculus', as Foucault says, for the logical interrelationships of the particular elements it brings to visibility. In the case of Harvey, these elements or primitives can be said to be the particularities of the particular body, including the five qualities of situation, shape, etc. that should be considered for 'each instrumental part' (Harvey 1964, p. 21).

As illustrated below, these epochal, epistemic characteristics have significant implications for Harvey's anatomical studies of the motion of the heart and blood, which integrates the widest range of particulars. Early on in his lectures, Harvey quotes a contemporary of Vesalius (Realdus Columbus, 1516-1559) and appeals to something that is clearly not shown - a vivisected and dead dog — but that is rendered only by speech. This is a type of speech that is particularly vivid yet dispassionate. This occurs in Harvey's commentary of the nature of liquid that surrounds the heart and is contained within a sac (the pericardium) that protects this vital organ:

As Columbus has said it [this liquid] is found both in living and in dead dogs. Of a truth there is more in the dead, as in the case of those who are handed in the sun. . . The water [in the pericardium] is free from bitterness and the taste of salt, yet WH it contains soda, slippery, scouring as in butcher's hands. (Harvey 1964, p. 
Harvey here is indeed making 'nature visible from its primary elements' (Foucault 1970, p. 61). In this case, however, these elements extend well beyond the qualities of situation, shape, amount, movement, division, and include things like the scouring quality and the (lack of) taste of the liquid contained in the pericardium. As Harvey also mixes keenly observed particulars typical of the classical episteme with observations of an earlier anatomist (Dominicus Leonus, from the previous century, who in turn is echoing the ancient anatomist, Galen). With references to the humors of the pre-classical episteme, Harvey describes the heart's auricle, today known as the atrium:

The auricles are black in colour and made of skin that they may allow for distention. The left auricle is rougher on the outside, more pointed, smaller, harder and a little fleshier and thicker in texture than the right auricle. It is provided with three kinds of fibres; Dominicus Leonus, p. 695 [sic]. Inside it is wrinkled. I have seen it furnished with fibres as in the ventricle. It is so completely filled with blood that, if the blood be clotted in front of it, it can be taken for an imposthume [or abscess] particularly in those who are high-souled or choleric or burning with fever and choked. The use of the auricles is to be as it were storerooms for the heart. (Harvey 1964, p. 259)

Harvey's continuing reference to authorities, and particularly to the pre-classical notion of the choleric personality, clearly shows that (at this point) he has not fully extricated himself from the logic of resemblance typical of the pre-classical episteme. ${ }^{3}$ However, the concluding sentence of the passage above, saying that the 'use of the auricles is to be ... storerooms for the heart', shows that Harvey is simultaneously enacting of the logic and language of classical ways of knowing: Through the identification of a range of particulars, Harvey is working towards at least one of 'all their possible combinations' (Foucault 1970, p. 61): The point of the assertion is that the auricles are storerooms for blood, rather than abscesses or some other physical manifestation. Harvey can be seen as reaching a conclusion through a type of logic or 'universal calculus' that follows from the descriptions he has previously compiled.

To return briefly to Foucault's epistemic account in The Order of Things, Harvey's description can be seen as going even further in fulfilling the modes and characteristics of the classical episteme. This is evident in particular in Harvey's movement, in the last sentence, from an anatomical to an instrumentalized physiological description of the auricle as 'storeroom'. 'Thus,

In Classical analysis, the organ was defined by both its structure and its function; it was like a double-entry system which could be read exhaustively either from the point of view of the role it played (reproduction, for example), or from that of its

\footnotetext{
${ }^{3}$ Harvey's book on the circulation system in humans and animals, published 13 years after the Lumleian lectures, has far fewer of these references to previous and ancient anatomical authorities (Harvey 1889).
} 
morphological variables (form, magnitude, arrangement, and number): the two modes of decipherment coincided exactly, but they were nevertheless independent of one another-the first expressing the utilizable, the second the identifiable. (Foucault 1970, p. 263)

Harvey begins with an exhaustive explanation of that which is identifiable in the auricle, and then gives expression to the utilizable, the second coinciding with the first, and indeed in a sense deciphered through the first. This structure of Harvey's approach, which names and points to use and utility, is noticeably apparent in the Latin opening sentence of the introduction to De motu cordis: 'De cordis arteriarumque motu, pulsu, actione, usu, \& utilitatibus cogitanti [As we are considering the motion, pulse, action, use, and utility of the heart and arteries]' (Herveius, 1628, p. 10). ${ }^{4}$ It is this emphasis on utility and explicit functions particular to the heart that is central to Harvey's treatment of this organ. In working towards these, Harvey also provides further listings of many specific observations of the temperature, color, texture, position, and movement of the heart and its parts (in mammals, reptiles, insects, and other creatures at various stages after fertilization). He does so in this case to arrive at a compact and forceful conclusion that also decodes function (usus, utilitas) from description, and that has done much to ensure his place in the history of the science of physiology:

Action of the heart: thus relaxed [it] receives blood, contracted scups it over. The whole of the body responds to the artery as my breath in a glove. And of a truth for what purpose? Aristotle says for none but that it is a passive action like that which is seen in boiling pottage [or soup]. WH but when the heart is wounded it discharges not wind but blood. WH but that it is for some purpose is shown by its construction, its fibres, valves and the artery itself. WH is it cooled by the boiling movement of the blood? or are the parts warmed by the arterial blood which would explain why [or] when an artery is obstructed that piece of the body becomes cold? WH or is it to assist in the dissipating of heat in fevers and in other morbid conditions engendered by heat? In children its substance is loosely textured. (Harvey 1964, p. 273)

Harvey moves from this interrogation of Aristotle (who describes the heart as cleansing the blood in part by mixing it with air) to point out something new, on his own merit. This is the fact that the heart does not take in air but contains only blood. He is describing this specific organ in terms of its utilization (utilitas): the heart pushing the blood into the arteries for the purpose of circulating blood through the body via the extremities where arteries are joined to the veins:

\footnotetext{
${ }^{4}$ Subsequent translations have tended to replace Harvey's words 'use' [Lat. usus] and 'utility' [Lat. utilitas] by 'function'. However, the functional perspective was only emerging at the time and not yet recognized as such. That is, the translations superimpose a modern perspective on the text that did not yet exist at the time of Harvey, whose work contributed to the emergence of the functional perspective in the way Foucault (1970) describes it.
} 
WH it is certain from the structure of the heart that the blood is perpetually carried across through the lungs into the aorta as by two clacks of a water bellows to raise water. It is certain from the experiment of the ligature that there is a passage of the blood from the arteries to the veins. And for this reason it is certain that the perpetual movement of the blood in a circle is caused by the heart beat. (Harvey 1964, p. 273)

By labeling and classifying the individual organs according to their qualities or 'morphological variables', Harvey is the first to simultaneously decipher what today is called the function of the heart, essentially as it is understood today. ${ }^{5}$ Together with Descartes' (1664) description of the body as a machine, the heart subsequently is understood as a kind of bellows or pump for the circulation of blood.

It is important to observe, however, that although Harvey is here providing the basis for an account of the operation of the circulatory system, he does not go so far as to conceive of circulation in terms of its interdependent, systematic interrelationships. ${ }^{6}$ It remains, in Harvey's words, only 'the perpetual movement of the blood in a circle'. In keeping with Foucault's analysis, as quoted above, Harvey's concern is focused on the individual, identifiable organ. Anatomy and physiology are understood precisely in terms of this individuality of units of description and function, with each organ observed in relative isolation from one another and, significantly, from a larger systemic coherence. Foucault underscores this distinction by referring to the underlying systemic function of the respiratory system - whether it is manifest in fish or mammals - but he could just as well be speaking of the systemic, circulatory function of the heart:

It matters little, after all, that gills and lungs may have a few variables of form, magnitude, or number in common: they resemble one another because they are two varieties of that non-existent, abstract, unreal, unassignable organ, absent from all describable species, yet present in the animal kingdom in its entirety, which serves for respiration in general. . . the gills are to respiration in water what the lungs are to respiration in air. True, such relations were perfectly well known in the Classical age; but they were used only to determine functions; they were not used to establish the order of things within the space of nature. (Foucault 1970, p. 263-264)

Harvey's conclusions, as quoted above, clearly anticipate the possibility of a set of systematized relations in the process of circulation. However, as Foucault indicates, we need to look to developments after the classical age to see the establishment of 'the order of things within the space of nature' as a system of interdependent components.

\footnotetext{
${ }^{5}$ It is worth noting that this conception of the heart as a pump has been challenged since Harvey's time, particularly by philosopher, educationist, and esotericist Rudolf Steiner (among others). Steiner proposed that that this organ is 'not a pump forcing inert blood to move with pressure but that the blood was propelled with its own biological momentum, as can be seen in the embryo' (Marinelli et al. 1995, n.p.). This same source illustrates that some researchers have subsequently sought to substantiate Steiner's hypothesis. ${ }^{6}$ Descartes (1664), though almost completely defending the scholastic view, presents arteries as an extension of the heart (e.g., Gilson 1920).
} 


\section{The Contemporary Lecture}

Despite the continued importance of Harvey's explanation of the function of the heart as an individual organ, its presentation in the biology lectures of the contemporary teacher analyzed above is quite different from Harvey's account. Although the contemporary presentation relies on a range of signs and significations to convince, instruct, and inform, including examples and analogies, these instructional means are in many cases materially different from those in Harvey, and are understood and mobilized in a rather different way. It is also significant, of course, that the material evidence for both the $17^{\text {th }}$ and $21^{\text {st }}$ century lectures that serves as the basis for the analysis presented in this paper is different. Harvey's lecture is, out of necessity, reconstructed from notes and commentary (albeit fairly detailed ones); the performance of the contemporary lecturer, however, is reconstructed now (and also in the opening analysis, above) through video and audio recordings, capturing not only the modern lecturer's words and use of realia, but also his gestures and even cadences of speech or prosody. All the same, we show that these two examples of the anatomy lecture are comparable, and that for all their manifest similarities, each is representative of its epistemic moment in history.

The contemporary series of lectures on the circulatory system on which we draw here, spanned a total of seven lessons. It began with the introduction of the heart. In these lectures, the heart, its parts and their functions, are performed across a range of presentational devices, including spoken words, (iconic, deictic) gestures, written text and signs, prosody, and inscriptions over and about which the talk and gesture occurred. For example, the instructor introduced the basic structure of the heart over and about a diagram that focused on the four-part structure of the heart that is related to the different contributing function to within the circulatory system. (In the following transcription, each hyphen corresponds to about $1 / 4$ seconds; underlining marks the extent of a gesture verbally described in double parentheses and italics.)

The heart has four chambers |-----| the top ones are the receiving chambers ((gestures 'receiving') $)|--|$ The heart has four chambers $|-----|$ the top ones are the receiving chambers ((draws arrow pointing into right atrium $))|--|$ flow $|-------|$ in ((draws arrow pointing into left diagram $))$. |-------------| In uh Latin I think it is Latin there is the a name for the front room in the house $|--|$ the place where people enter and arrive and it is the $|--|$ atrium $|-----|$ in churches we called it foyer |--| uh the front entrance in our school |----| the word atrium $|--|$ is |------------| ((writes 'atrium' on the chalkboard $))$ just means a receiving area ((two-handed receiving gesture)) or entranceway and so this then becomes the right $|---|$ atrium and left atrium ((notes ' $R A$ ' and 'LA' in diagram, similar to figures 7 and 8$)$ ) |------------| there're |--| empty spaces ((gesture of space between two hands)) in the heart? |-| called ventricles $|--|$ there're empty spaces in the heart $|-|$ ( (points to diagram)) called ventricles $|--|$ and this is the right ventricle $|----|$ ((notes ' $R V$ ' and ' $L V$ ' in diagram, figure 8$)$ ) and the left ventricle $|--------|$ the vent if the atria are $\mid-$ -| receiving areas the ventricles are the big pumps ((receiving gesture)) |---| these 
are the pumping chambers.

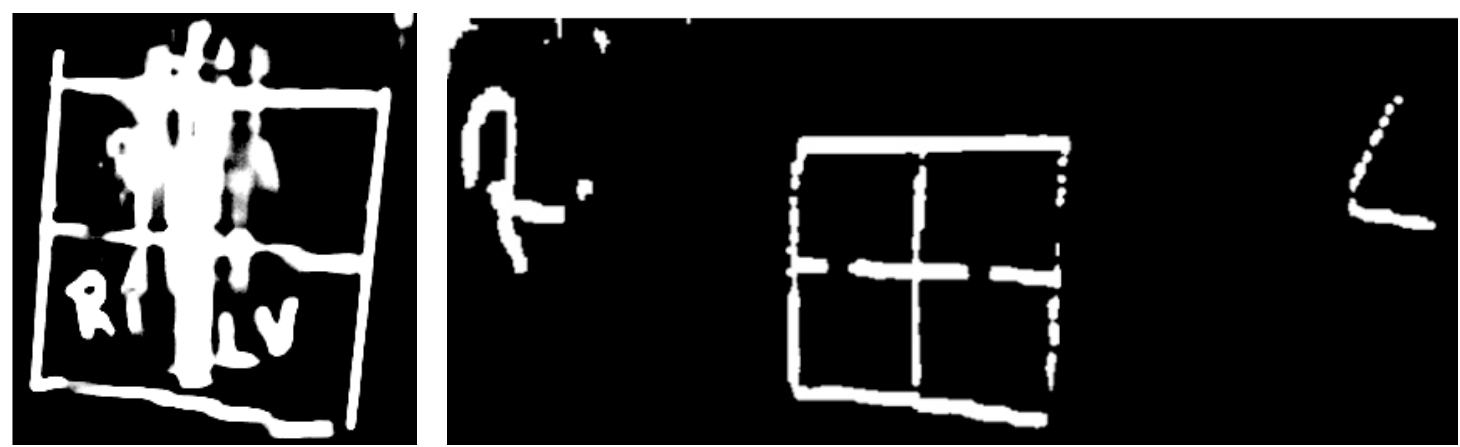

Figures 7 and 8: Abstract diagrams featured throughout the 7 lectures on the heart and circulatory system.

In this excerpt from the lectures, the teacher presented the atrium and ventricle, each of which exists twice: on the left and right sides of the heart. He used an analogy of the front room of a house or church to relate the technical term atrium to the experience of the front room in a house or other structure. He introduced the functions of the two types of chambers: the atria are the receiving areas, whereas the ventricles are the 'big pumps'.

An important part of the lecture form, as mentioned above, are the iconic gestures, which make visible some aspects that Harvey would have seen during a vivisection, and which would have been familiar to his physician audiences. Harvey described in his own lecture that the heart, when studied in its movement, can be seen to become erect, hard, and of diminished size. These are precisely the particulars of the biology teacher's body as he enacted or performs a contraction of the heart (figures 9-11), where gestures bear a metaphorical function that subsequently is conferred to the concepts of science (Roth and Lawless 2002a). The movement begins with the body in a lowered position with the elbows out sideward the hands held as if these were touching the outside of a big drum (figure 9). As the hands moved inward, the upper body moved upward (figure 10) coming to an erect position when the hands had reached their closest position (figure 11).

Precisely coordinated with the movement is the articulation of the verb 'contracting'. We can literally see in the movement the constriction that occurs simultaneous with the erection. Prosodically, there is an emphasis on the core part: conTRACting.
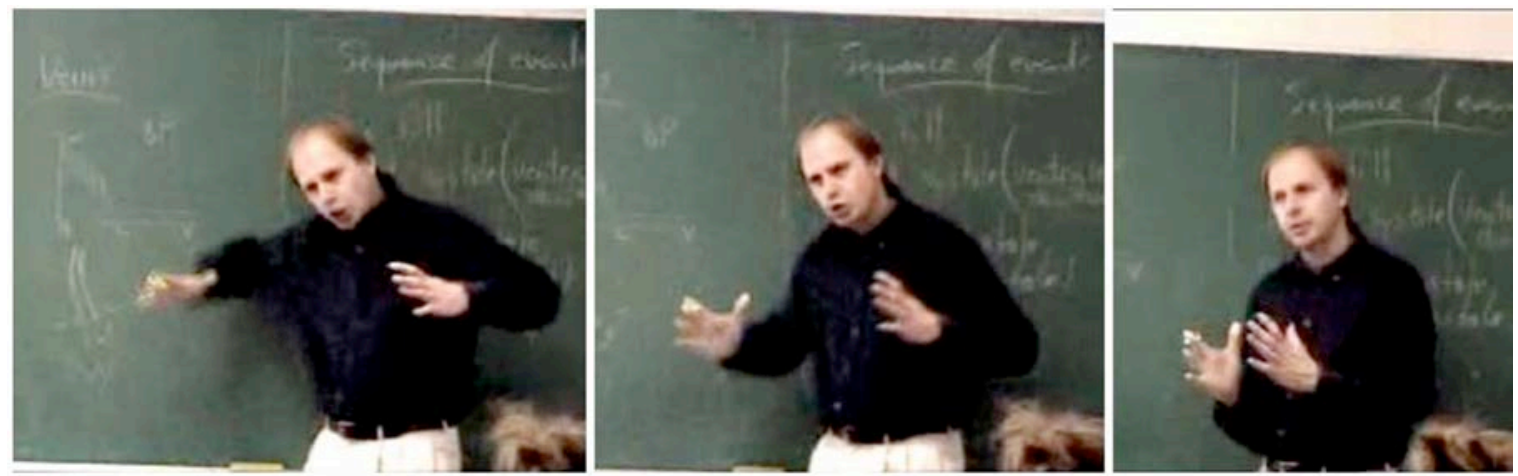

Figures 9-11: Gestures made while enunciating: 'conTRACTing' 
It is important to note that the teacher begins with both a 3-D model and a naturalistic diagram of the heart, but as the course progresses, the dominant representation of the heart is a schematic, four-part diagram introduced above (figures 7 and 8). In their abstraction, these simple diagrams did not consist of more than a square box divided by two lines into four areas denoting the four chambers of the heart; the left and right ventricle are identified by means of the letter pairs ' $L V$ ' and ' $R V$ '. (In the end, even the LV and RV no longer are marked, e.g., figure 7.) As the teacher said 'The heart takes it from the left ventricle up and out', his right hand with index finger stretched out performs a movement that begins at the 'chamber' marked 'LV' and moves, along the center line of the diagram (figure 7), 'up and out'.

These diagrams and the labels focus on the function of the heart as a pump with chambers, in the terms described by Harvey. However, these illustrations clearly depart from Harvey's imperatives to work with 'the peculiarities of the particular body' including the qualities of situation, shape, amount, movement, division. This contemporary diagram is cleansed of this specificity concerning situation, shape, amount, and movement, with only the quality of division remaining: This reduction, can be said to lead to an amplification that comes from a gain in information as the diagram applies to more cases and therefore increases in universality (Latour 1999). As the words and gestures of the lecturer described above make clear, what is important, the real phenomena, are function and movement. The diagram was not concerned to show the differences in size and shape of the ventricles or auricles that were of some note for Harvey; the texture or acidity of the components associated with these parts is clearly a matter of irrelevance in these representations. To return to Foucault, these differences can be further explained by adapting his characterization of the respiratory system, quoted earlier:

It matters little [that the diagram of the heart and an actual instance of the same] may have a few variables of form, magnitude, or number in common: they resemble one another because they are two varieties of that non-existent, abstract, unreal, unassignable organ, absent from all describable species, yet present in the animal kingdom in its entirety, which serves for [circulation] in general. (Foucault 1970, p. 263-264)

In being removed from its particularity, and placed into the context of the circulatory system and its various foundations, the heart ceases to be this or that heart with its own specific colors, shapes and textures - all of which may be modified in their appearance in children, dogs or in other contexts. Rendered as four rectilinear, contiguous chambers, Foucault's implied characterization of the heart as 'non-existent, abstract, unreal, unassignable organ' appears fully realized in this contemporary example. At the same time, however, something similarly 'unreal' is communicated in the gestures and the realia of the contemporary teacher: not an organ, but a motion, function or performance, understood in terms of its efficiency, how well it performs, rather than in reference to any other particular criteria. This applies, of course, not only to the heart, but also to any other aspect of human biology understood in broadly contemporary terms. Foucault explains: 
It is upon the projected surface of biology that man appears as a being possessing functions - receiving stimuli ... reacting to them, adapting himself, evolving, submitting to the demands of an environment, coming to terms with the modifications it imposes, seeking to erase imbalances, acting in accordance with regularities, having, in short, conditions of existence and the possibility of finding average norms of adjustment which permit him to perform his functions. (Foucault 1970, p. 263-264)

To understand anatomy and physiology in the contemporary educational context is to understand these functions. The functional approach to biology, which emphasizes the laws of systems has been described as much more powerful than the structural approach, emphasizes the laws of the components (Lahiri 1977). It is not surprising that this is precisely the way in which this biology course was organized and presented to students in courses: In terms of the different systems and their functions, beginning with the skeletal (a topic not covered at all in Harvey), then moving to the muscular, respiratory, vascular, neural, and from there typically to more specific systems in the body.

\section{Anatomy Lectures Then and Now: Epistemological Changes}

Even with all of the differences in biology today compared with Harvey's time, there are significant points of commonality. This commonality can be seen as sustaining Harvey's aforementioned canonical status in anatomy and physiology today - and also in a range of contexts in which circulation has become a figure of thought such as economics (Foucault 1970) or, more recently, science studies (Latour 1999). This point of commonality is identified in Harvey's forceful conclusion 'that the perpetual movement of the blood in a circle is caused by the heart beat' (Harvey 1964, p. 273). What we show to be happening in the intervening 400 years is not so much a change in the content of the anatomy lecture nor a shift in the basics of its manifest form or function. Instead, the change can be described as occurring in the expansion of the 'circle' mentioned by Harvey. Rather than being a secondary phenomenon subsumed to the function of the heart, this systemic circle or cycle has become the primary concern, with the heart reduced to one of a number of functions within this circle - albeit a key function. This circle, in other words, has become a vast circular system, one of many, layered systems that together make up the body. As indicated above, the prevalence of systemic function in present day biology can be confirmed by a quick glance at any basic textbook on anatomy and physiology (e.g., Roberts 1986): These are not organized, as are Harvey's lectures, around particular organs and their appearance and motion. Instead, these texts are structured via successive systems, from the respiratory system, through the pulmonary, to the nervous, digestive and reproductive.

This emphasis on the system and its endogenous, interdependent functions can also be seen as an explanation for the relative absence of vivid, literal realia and language on the part of the modern lecturer. Just as Harvey is able to rely on a vivid and colorful language of tastes, textures, shapes, and hues - and descriptions of vivisected and dead animals of various kinds- the contemporary lecturer is depends on a kind of systematic, explanatory coherence and consistency. Because the ultimate 'truth' of the heart in modern biology is 
its systemic function — something that is ultimately invisible - it is possible for today's lecturer to dispense with realia showing any verisimilitude with the heart and its motion relatively early in the lecture. Although the present-day lecturer is deprived of the assurance - upon which Harvey relies - that his words and gestures will make the 'truth' of what he is describing visible to his students, he is supported by other attributes central to the modern or post-classical episteme as described by Foucault: Namely on 'systemics' and the evidence of systematic performance - whether these are manifest in physiology and to take this one step further, also in his own actions as a teacher

Insofar as organs like the heart are reduced to their function within systems in the modern lecture, they are no longer specific physical manifestations whose texture, color, and shape are to be described in a precise language. Instead, they are functions that are to be captured and conveyed through a performance, in other words, via instruction that is itself viewed in similarly functionalist and systemic terms. The significance of the contemporary teacher's work is not framed in terms of informing a small aristocratic audience who share a familiarity with the works of Aristotle, Galen and more recent authorities - as is clear from the many off-handed references to various sources in Harvey. Instead, it is to communicate to constantly renewed audiences the functions of different systems, to provide them with epistemic access to a medical system whose interventions and treatments are similarly based on systemics, to achieve optimized or average norms of adjustment which permit us to perform our own functions in our lives.

This comparison of the modern and early modern anatomy lecture offers as many points of similarity and continuity as it does changes and contrasts. A basic repertoire of methods and techniques remains in place, from the iconic and deictic gestures of Vesalius to those of the contemporary lecturer before/against the blackboard and in front of his students. In addition, the basic principles or content that is communicated in both cases is quite similar: The heart pushes the blood, and its operation (both in its appearance and its underlying functions) requires careful description and interpretation. It seems likely that it is one of the scientific phenomena mentioned at the outset whose understanding, for many students, has live enactments in the classroom as its prerequisite. The changes that are much more clearly manifest in these instantiations of the lecture over time seem to have much more to do with basic epistemic conditions and presuppositions than with any transformations in the means through which knowledge is reproduced. The change that is manifest in these pedagogical performances seems to be closely connected with the authorization of the knowledge that is produced and reproduced through these performances. In the case of Harvey (and presumably also of Vesalius) the knowledge in question is based on empirical or rather, sensory exploration. From there, it is authorized in terms of its similarity to and differences from previous (and particularly, ancient) accounts. In the case of the modern lecture, it is clear that this authorization is quite different: It is not justified on the basis of historical accounts and current sensory observations. Instead, knowledge is underwritten through paradigms of systematicity and performativity. In the early modern and late modern lectures, the efficacy of the reproduction of knowledge is not substantially increased or diminished through new technologies or techniques. Laurillard, who was quoted at the outset as attributing the persistence of the lecture format to 'enfeebling tradition' would perhaps do well to look also at the 400 year tradition behind the phenomenon being demonstrated in this lecture, 
and the intervening epistemic changes which make issues of performance and systemic efficacy seem so singularly important. The changes that are evident in instructional means and technologies - the switch in realia from cadaver to model and diagram, from sensorial description to schematic reduction - are detectable only in the longue durée, one of the principles of historical analysis that remained central in Foucault's work throughout his life.

\section{References}

Bavelas, J. B., Chovil, N., Lawrie, D. A., \& Wade, A. (1992). Interactive gestures. Discourse Processes, 15, 469-489.

Brown, G., \& Manogue, M. (2001). AMEE medical education Guide No. 22: Refreshing lecturing: A guide for lecturers. Medical Teacher, 23 (3), 231-244.

Collins, A., \& R. Halverson. (2010). The second educational revolution: rethinking education in the age of technology. Journal of Computer Assisted Learning, 1(26) 1827.

Descartes, R. (1664). L'homme de René Descartes et un traitté de la formation du foetus du mesme auteur [The man according to Rene Descartes and a treatise on the formation of the foetus by the same author]. Paris, France: Charles Angot.

Foucault, M. (1970). The order of things. New York, NY: Random House.

Gilson, E. (1920). Descartes et Harvey [Descartes and Harvey]. Revue Philosophique de la France et de l'Étranger, 90, 432-458.

Harveius, G. [Harvey, W.] (1628). Exercitatio anatomica de motu cordis et sanguinis in animalibus [Anatomical study on the motion of the heart and blood in animals]. Frankfurt, Germany: G. Fitzerius.

Harvey, W. (1889). On the motion of the heart and blood in animals. London, UK: George Bell.

Harvey, W. (1964). The anatomical lectures of William Harvey. Prelectiones anatomie universalis de musculis (G. Whitteridge, Ed.). Edinburgh, UK: E. \& S. Livingstone.

Heidegger, M. (1977). Sein und Zeit. Tübingen, Germany: Max Niemeyer.

Husserl, E. (1976). Husserliana-Gesammelte Werke Band VI. Die Krisis der europäischen Wissenschaften und die transzendentale Phänomenologie [Husserliana-Collected works vol. 6. The crisis of the European sciences and transcendental phenomenology]. The Hague, The Netherlands: Martinus Nijhoff.

Knoblauch, H. (2008). The performance of knowledge: pointing and knowledge in Powerpoint presentations. Cultural Sociology, 2, 75-97.

Lahiri, A. (1977). The functional approach in biology. BioSystems, 9, 57-68.

Latour, B. (1999). Pandora's hope: essays on the reality of science studies. Cambridge, MA: Harvard University Press.

Marinelli, R., Fuerst, B., van der Zee, H., McGinn, A., \& Marinelli, W. (Fall-Winter 1995). The heart is not a pump: A refutation of the pressure propulsion premise of heart function. Frontier Perspectives, 5 (1) n.p. Accessed March 15, 2013 at http://www.rsarchive.org/RelArtic/Marinelli/

McNeill, D. (2005). Gesture and thought. Chicago, IL: Chicago University Press.

McNulty, J. A., Hoyt, A., Chandrasekhar, A. J., Espiritu, B., Gruener, G., Price, J. Jr., \& 
Naheedy, R. (2012). A three-year study of lecture multimedia utilization in the medical curriculum: Associations with performances in the basic sciences. Medical Science Educator, 21 (1), 29-36.

Pillans, J. (1852). The rationale of discipline, as exemplified in the high school of Edinburgh. Edinburgh: MacLachlan \& Stewart.

Pozzer-Ardenghi, L., \& Roth, W.-M. (2005). Photographs in lectures: Gestures as meaning-making resources. Linguistics \& Education, 15, 275-293.

Pozzer-Ardenghi, L., \& Roth, W.-M. (2009). How do we know he is not talking about himself? Demonstrations in science classrooms. Journal of Pragmatics, 41, 684-698.

Prober, C. G., \& Heath, C. (2012). Lecture halls without lectures-A proposal for medical education. The New England Journal of Medicine, 366 (18), 1657-1659.

Richardson Bruna, K. \& Vann, R. (2007). On pigs \& packers: Radically contextualizing a practice of science with Mexican immigrant students. Cultural Studies of Science Education, 2, 19-59.

Roberts, M. B. V. (1986). Biology: A functional approach 4th ed. Cheltenham, UK: Nelson.

Roth, W.-M., \& Bowen, G. M. (1999a). Complexities of graphical representations during lectures: A phenomenological approach. Learning and Instruction, 9, 235-255.

Roth, W.-M., \& Bowen, G. M. (1999b). Decalages in talk and gesture: Visual and verbal semiotics of ecology lectures. Linguistics \& Education, 10, 335-358.

Roth, W.-M., \& Lawless, D. (2002a). Scientific investigations, metaphorical gestures, and the emergence of abstract scientific concepts. Learning and Instruction, 12, 285-304.

Roth, W.-M., \& Lawless, D. (2002b). When up is down and down is up: Body orientation, proximity and gestures as resources for listeners. Language in Society, 31, $1-28$.

Roth, W.-M., McRobbie, C., Lucas, K. B., \& Boutonné, S. (1997). Why do students fail to learn from demonstrations? A social practice perspective on learning in physics. Journal of Research in Science Teaching, 34, 509-533.

Roth, W.-M., \& Tobin, K. (1996). Aristotle and natural observation versus Galileo and scientific experiment: An analysis of lectures in physics for elementary teachers in terms of discourse and inscriptions. Journal of Research in Science Teaching, 33, $135-157$.

Schreiber, B. E., Fukuta, J., \& Gordon, F. (2010). Live lecture versus video podcast in undergraduate medical education: A randomized controlled trial. BMC Medical Education, 10 (68). Accessed October 16, 2012 at www.biomedcentral.com/14726920/10/68

van Eijck, M., \& Roth, W.-M. (2011). Cultural diversity in science education through novelization: Against the epicization of science and cultural centralization. Journal of Research in Science Teaching, 48, 824-847.

Weinstein, M., \& Broda, M. (2009). Resuscitating the critical in the biological grotesque: Blood, guts, biomachismo in science/education and human guinea pig discourse. Cultural Studies of Science Education, 4, 761-780.

Whitteridge, G. (1964). Introduction. In G. Whitteridge (Ed.), The anatomical lectures of William Harvey (pp. xix-1xiv). Edinburgh, UK: E. \& S. Livingstone. 